\title{
VALIDAÇÃO DO SISTEMA DE AUTOMAÇÃO DE NÍVEL DIGITAL APLICADO NA DETERMINAÇÃO DE RECALQUES
}

\section{Validation of applied digital level of automation system in determining the settlements}

\author{
André Luiz Tedeschi ${ }^{1}$ \\ Pedro Luis Faggion ${ }^{1}$ \\ Silvio Henrique Delleposte Andolfato ${ }^{2}$
}

\begin{abstract}
1 Universidade Federal do Paraná1 Departamento de Geomática. Caixa postal 19001- Centro Politécnico Jardim das Américas-81531-970.Curitiba/PR,Brasil.

Email andrecartografico@yahoo.com.br; pedro.faggion@ufpr.com

2 Universidade Tecnológica Federal do Paraná² Departamento de Agrimensura. Caixa postal 571-

Campus Pato Branco, via do conhecimento, Km 1- 85503-390 Pato Branco/PR, Brasil.

Email:andolfato@utfpr.edu.br
\end{abstract}

\section{Resumo:}

O objetivo desta pesquisa é validar um sistema de automação de níveis digitais, desenvolvido em uma tese de doutorado (Andolfato, 2010) e apresentado ao curso de pós-graduação em ciências Geodésicas da UFPR. O procedimento de validação consiste em utilizar o nível digital através do nivelamento geométrico pelo método das visadas extremas para determinar desníveis entre alvos distribuídos com diferentes distâncias em relação ao nível. A simulação do recalque foi realizada através de pinos fixados em várias colunas, em diferentes alturas. A primeira fase consistiu em determinar os desníveis e consequentemente os recalques com o sistema convencional, utilizando um técnico como observador. Posteriormente estes mesmos recalques foram determinados utilizando o SAND (Sistema de Automação de Nível Digital). Depois de concluídos os levantamentos, os resultados obtidos com o SAND foram comparados com os do levantamento convencional e constatou-se que as diferenças de valores entre os recalques detectados/calculados por ambos os métodos variaram no décimo do milímetro. As variâncias dos recalques calculados, em ambos os métodos, foram testadas utilizando o teste $\mathrm{F}$ de Snedecor ao nível de significância de 5\% e constatou-se que a maioria dos resultados passou no teste de hipótese, ou seja, foram determinados com o mesmo grau de precisão.

Palavras-chave: Nível digital, monitoramento, automação, recalque, SAND

\begin{abstract}
:
The main goal of this research is to validate a digital level automation system developed in a $\mathrm{PhD}$. Thesis by Andolfato (2010) and presented to the Geodetic Science postgraduate program from Federal University of Paraná. The validation procedure consists in applying the digital level
\end{abstract}


to determine height differences between targets distributed at different distances in relation to the digital level. Settlements simulations were performed by fixing pins in several wall columns at different heights. In the first stage the height differences and consequently the settlements were determinated by the conventional leveling method where observations were acquired by a qualified technical. Afterwards, these same differences were determined using the method named SAND - Sistema de Automação de Nível Digital (Digital Level Automation System). After finished the surveyings, the results obtained by the SAND method were compared with results from conventional method and it was observed differences within the tenth of millimeter in the computed settlements. The variances of the height differences in both cases were tested using the F- Snedecor test, at a significance level of 5\%, and most values were approved, what means that they were determined with the same degree of precision.

Keywords: Digital level, monitoring, automation, settlement, SAND

\section{Introdução}

A automação impactou de forma significativa os levantamentos geodésicos de precisão. Instrumentos como corrente de agrimensor, goniômetros, teodolitos, níveis óptico-mecânicos entre outros foram gradativamente sendo substituídos por equipamentos mais modernos, com capacidade de processamento que proporcionaram melhoras significativas na precisão, na acurácia e voltadas para produtividade em campo.

A rápida evolução nas áreas da engenharia, da microeletrônica e da computação propiciou à instrumentação geodésica este salto de qualidade. Um exemplo disso são as estações totais que executam medidas eletrônicas de distâncias, leituras automáticas de direções e reconhecimento automático de alvos além de realizar os cálculos de coordenadas em tempo real.

Esta evolução também pode ser presenciada nos níveis geodésicos, que sofreram grandes mudanças no modo de leitura, como no caso dos níveis digitais. Estes representam um avanço nas técnicas de nivelamento geométrico, pois utilizam o conceito inovador de leitura de miras com código de barras (Veiga, 2000). Quando se utiliza o nível digital em levantamentos, há uma redução de até $50 \%$ do tempo de trabalho em função da rápida realização da leitura, além da agilidade e segurança no processamento e também da possibilidade de salvar/gravar estes dados em um dispositivo de armazenamento (Aksamitauskas et al.,2008). Mas estes equipamentos carecem de uma total automação, pois ainda há a necessidade de se operar manualmente os movimentos de pontaria e de visada aos alvos de interesse, o que não permite ou dificulta o monitoramento contínuo.

A ausência de um sistema de monitoramento automatizado para o nível digital torna-se um fator limitante quando se pensa em detecção de possíveis recalques, sendo estes deslocamentos verticais e descendentes que as estruturas podem sofrer durante sua edificação ou mesmo depois (Milititsky et al., 2008). O grande benefício da automação e mecanização desse processo encontra respaldo quando se pensa em um sistema voltado ao monitoramento contínuo, envolvendo grande volume de dados e minimizando erros de observação oriundos do observador (Veiga, 2000; Nadal, 2008; Guilani e Wolf, 2012).

Atentando a este problema, Andolfato (2010) propôs e construiu um sistema de automação para nível digital (SAND), desenvolvido especificamente para o nível digital DNA 03, do fabricante 
LEICA. Este sistema automatiza o movimento horizontal do nível e o movimento de focalização do alvo, apresentando bons resultados com relação à leitura e detecção de alvos.

Entretanto, para uma validação completa deste sistema, uma investigação mais ampla se faz necessária para verificação do funcionamento do sistema em situações em que ocorrem variações nas medidas observadas durante um determinado período de tempo, não apenas para verificar sua capacidade de detectar pequenos deslocamentos verticais, mas também de testar seus limites de operacionalidade no que tange a distância nível/alvo, estabilidade de calagem durante o processo de observação dos alvos e o movimento de focalização para tomada da leitura. O objetivo principal desta pesquisa é validar o sistema de automação de nível digital(SAND) através de ensaios de nivelamento geométrico e simulações de recalque feitas com a utilização de alvos distribuídos em uma área pré-determinada.

O processo de validação compreende o emprego da técnica de nivelamento geométrico chamado de visadas extremas (Kahmen e Faig,1988; Ghilani e Wolf, 2012) com o uso do nível digital DNA 03, tanto de maneira convencional (utilizando um técnico como observador, sem nenhuma automação no processo) quanto com a utilização do sistema de automação (SAND) e comparar seus resultados ao final dos experimentos. Para verificar se o SAND infere algum tipo de influência na precisão do resultado, foi utilizado teste de hipótese F de Snedecor (Guerra, 1982) para estudar generalizações sobre as variâncias das amostras coletadas durante os ensaios. Realizaram-se também ensaios noturnos com o SAND para verificar sua resposta de detecção em ambientes com pouca luminosidade. Os resultados alcançados serão descritos e analisados, sendo ao final, feitas as devidas considerações.

\section{Automação do monitoramento altimétrico}

Segundo Miranda (2012) o monitoramento trata do acompanhamento e estudo, contínuo e sistemático, do comportamento de fenômenos, eventos e situações específicas cujas condições desejam-se identificar, avaliar e comparar. Desta forma, é possível estudar as tendências ao longo do tempo, ou seja, verificar as condições presentes, projetando situações futuras. Corrêa (2012) ressalta que no Monitoramento Geodésico o acompanhamento é realizado através da comparação de coordenadas geodésicas entre duas ou mais épocas distintas. A importância do monitoramento de recalques em estruturas está intimamente relacionada a questões como segurança e durabilidade das construções, que precisam ser acompanhadas constantemente desde o início da obra, como controle de qualidade, verificando seu comportamento durante sua construção e utilização.

Kuang (1996) cita como principais métodos de monitoramento geodésico a poligonação, triangulação, trilateração, levantamentos utilizando tecnologia GNSS e o nivelamento geométrico e Granemann (2005) salienta que os instrumentos que mais se destacam no monitoramento geodésico de estruturas são as estações totais, níveis, miras de ínvar, trenas, prismas de reflexão e gravímetros. Dentro desse contexto, a automação dos instrumentos geodésicos de precisão auxilia na otimização do processo de leitura, no armazenamento de grande volume de dados e no processamento dos dados assim como na redução do tempo de trabalho, aumentando a produtividade e minimizando erros que acompanham o processo de mensuração. 
Um exemplo disso são as estações totais, que executam medidas eletrônicas de distâncias, leituras automáticas de direções e reconhecimento automático de alvos além de realizar os cálculos de coordenadas em tempo real. Os níveis digitais, embora também tenham sofrido impactos significativos com a era da tecnologia que otimizaram seu uso e rendimento em trabalhos dos mais diversos, ainda carecem de uma total automação, como já ocorre com as estações totais. Pelegrinelli et al. (2013) ressaltam que apesar de existirem estudos e protótipos de sistema de automação para níveis digitais, ainda há certa resistência para seu incentivo devido ao seu custo benefício. Mesmo assim, protótipos de baixo custo que automatizam o movimento horizontal micrométrico para detecção automática de alvos e movimento de focalização do alvo já foram desenvolvidos para tentar contornar este problema e incentivar a produção em larga escala deste tipo de produto.

Um exemplo de protótipo de automação para nível digital pode ser encontrado em Pellegrinelli et al.(2013). Neste artigo explica-se como foi desenvolvido um sistema de automação para o nível digital DNA 03 para permitir o monitoramento automático e contínuo de deformações em estruturas sem comprometer seu uso manual no nivelamento. Este sistema foi concebido através de um mecanismo avançado com base em micro motores elétricos e codificadores acoplados com o objetivo de estabilizar o movimento de rotação do nível e a repetitividade da pontaria nos alvos (miras). Empresas como a alemã Angerer-CPS (2015) e a suíça Solexperts (2015) também desenvolveram protótipos que automatizam os movimentos horizontais e de focalização das lentes de colimação dos níveis digitais, permitindo monitoramento automático e contínuo de estruturas com análise de dados em tempo real. No Brasil, o trabalho de Andolfato (2010) na área de automação de nível geodésico é pioneiro.

\section{Sistema de Automação de Nível Digital (SAND)}

O Sistema de automação de Nível Digital (SAND) é semiautomático, desenvolvido para o nível DNA 03 da Leica Geosystem, e possibilita a automatização tanto do movimento horizontal do nível quanto do movimento de focalização da imagem para realização de leituras em miras com códigos de barras. A sua natureza semiautomática se dá pela necessidade de alimentar, num primeiro momento e de forma manual, o sistema com informações referente ao número de passos tanto para o movimento horizontal, que irá efetuar a pontaria nos alvos, quanto para o sistema de ajuste de foco, que possibilitará o reconhecimento do alvo pelo nível digital.

O SAND possui basicamente duas componentes que formam sua base operacional: o hardware e o software. No componente hardware, destacam-se os seguintes elementos eletromecânicos:

-motor de passo: é um transdutor que converte energia elétrica em movimento controlado através de pulsos, o que possibilita o deslocamento por passo, sendo o passo o menor deslocamento angular. O SAND possui dois motores de passos acoplados em sua estrutura, como ilustrado na Figura 1, sendo um responsável pelo movimento micrométrico horizontal, possibilitando a pontaria nos alvos de interesse já previamente estabelecidos e o outro atuando no sistema de focalização do alvo ou mira. 


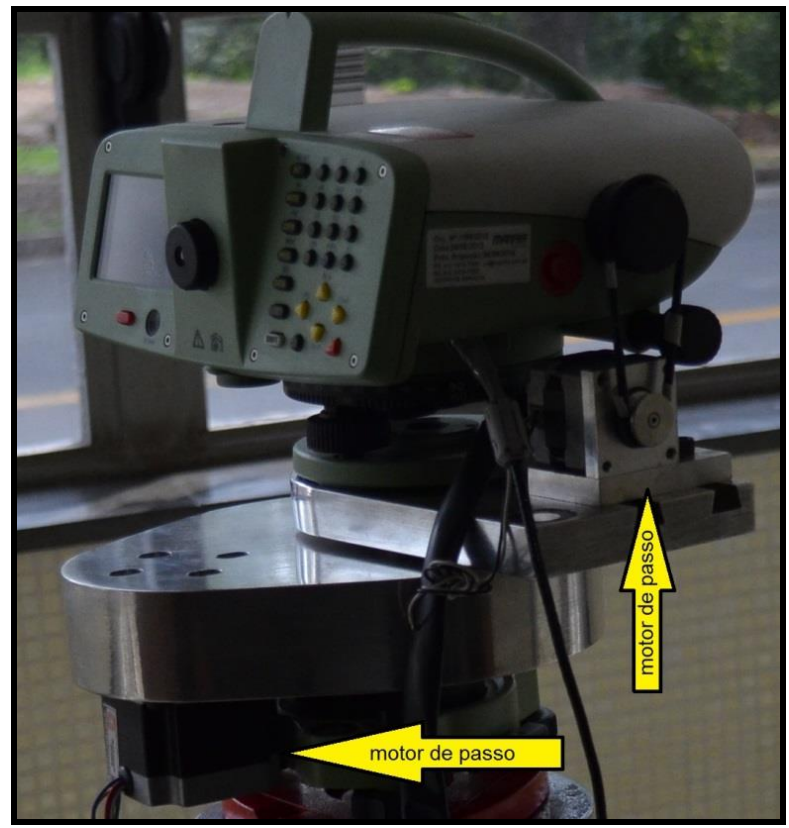

Figura 1: Motores de passo acoplados no DAMP Fonte: o autor

-DAMP: consiste de uma plataforma desenvolvida de modo a suportar os motores de passo e também o nível digital. Este dispositivo possui um braço eletromecânico que realizará o movimento horizontal do nível. O movimento de ajuste do foco ocorre através de um sistema de polias/engrenagens na base do dispositivo. Estes movimentos são comandados por um software específico, no caso o SAMN (Software para Automação do Nível).

Como parte constituinte do DAMP, destaca-se:

- base de sustentação, onde se apoiam o braço eletromecânico e o nível digital, conforme Figura 2. Aquele fará a função de rotacionar o nível horizontalmente (devidamente impulsionado pelo motor de passo), tanto no sentido horário quanto no sentido anti-horário, possibilitando uma ampla varredura de alvos que estão distribuídos na área de alcance do mesmo. A Figura 3 ilustra o sistema polia/engrenagem, com o uso de um anel de borracha, que será utilizado no ajuste do botão de foco do nível digital.

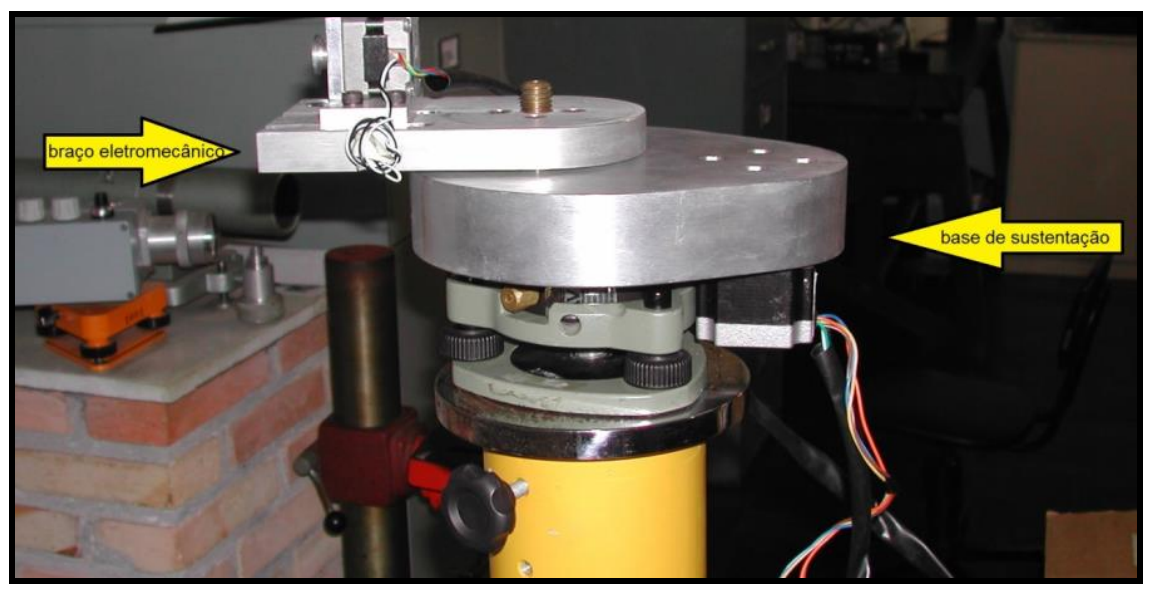

Figura 2: Componentes do DAMP Fonte: o autor 


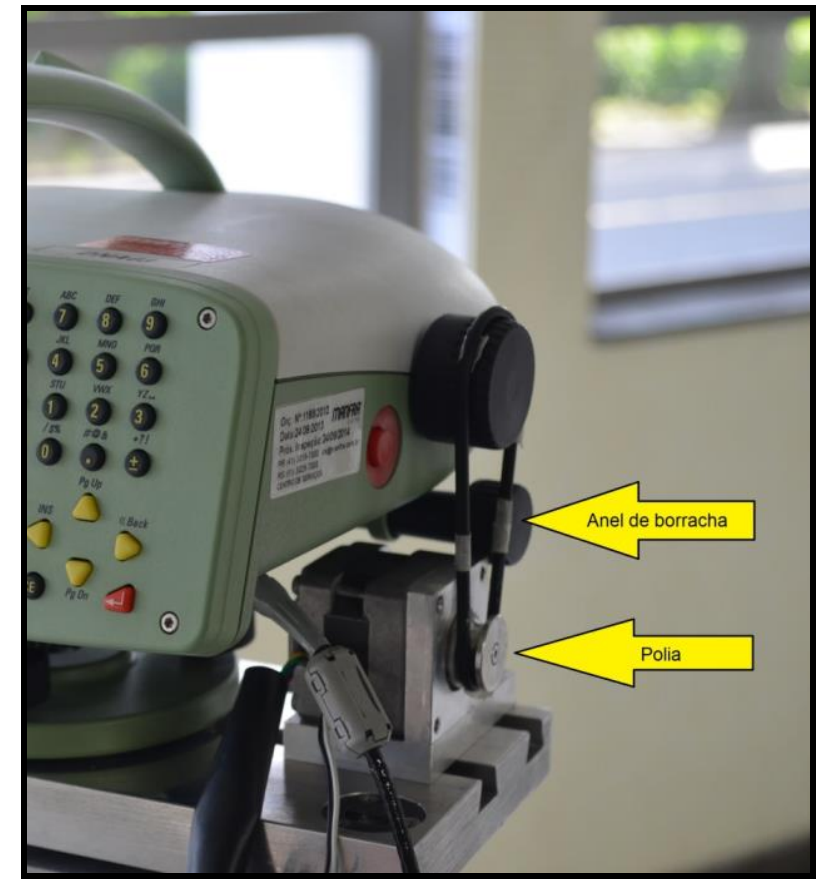

Figura 3: Anel de borracha e polia Fonte: o autor

A Figura 4 ilustra o Sistema de Automação de Níveis completo, sobre um tripé, com o nível digital sobre DAMP, na sua configuração necessária para a execução do monitoramento de uma estrutura.

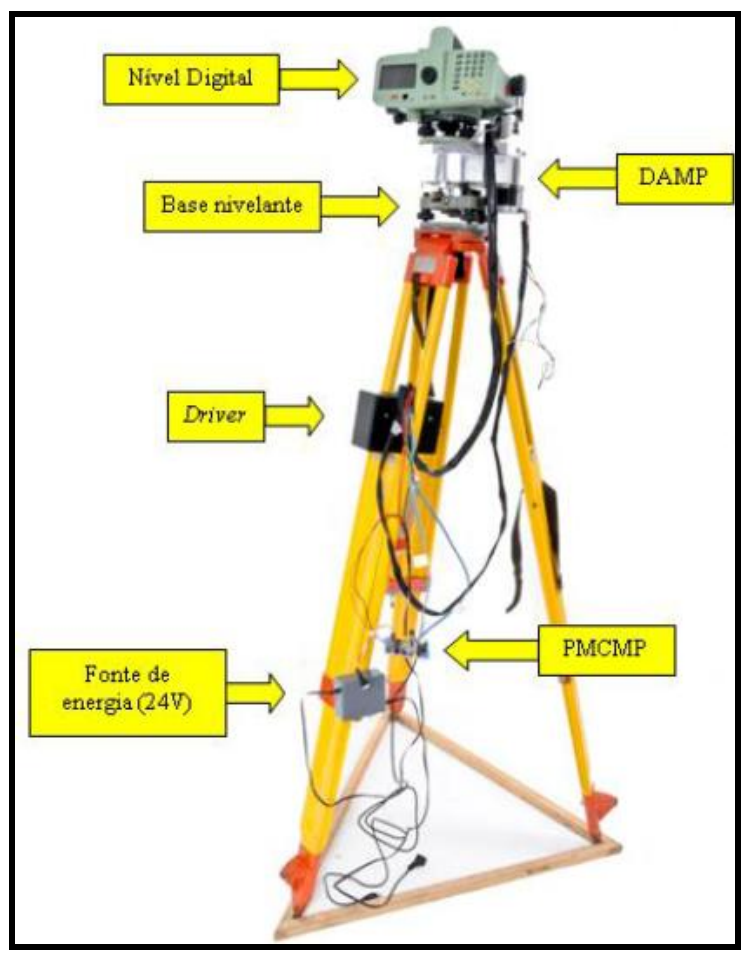

Figura 4: Sistema de automação de nível digital.

Fonte: Andolfato, 2010 
Com relação aos softwares, destacam-se:

- O módulo de programação do micro controlador:

- O módulo de automação do nível (SAMN):

A programação do micro controlador foi elaborada no software Arduino Alpha V. 0018, o qual é open source e pode ser obtido na internet. Um código foi desenvolvido e gravado na própria placa, via comunicação serial, através da porta USB. Maiores detalhes em Andolfato, 2010.

O software SAMN foi desenvolvido utilizando linguagem basic, com o compilador Visual Basic 6 e utilizando como banco de dados o mySQL 5, que tem sua distribuição gratuita para projetos livres de comercialização. As principais funções do SAMN são (ANDOLFATO, 2010):

1. Realizar a comunicação com o nível digital;

2. Efetuar a comunicação com a placa PMCMP para acionamento dos motores de passo;

3. Registrar no banco de dados os valores coletados pelo nível digital, armazenando dados de altura, distância, ponto de marcação e obra;

4. Efetuar as marcações de obras e pontos de marcação.

Cabe salientar que o SAMN necessita de dados de entrada para iniciar o funcionamento do sistema. A primeira série de observações nos alvos é feita de forma manual. A partir de um ponto zero determinado arbitrariamente, faz-se a contagem do número de passos necessários para a realização da pontaria e focalização deste para os alvos em questão, através do uso de um notebook. Este sistema possui um banco de dados que armazena o número de passos necessários para a realização da pontaria e focalização. Mais detalhes sobre o desenvolvimento e o funcionamento deste sistema podem ser encontrados em Andolfato (2010).

\section{Materiais e métodos}

As tarefas para a realização dos experimentos consistem em um primeiro momento executar o nivelamento geométrico pelo método das visadas extremas utilizando apenas o nível digital DNA03, sem o sistema de automação. Sobre o nível digital DNA 03 vale destacar que se trata de um equipamento destinado a levantamentos topográficos e geodésicos, desenvolvido pelo fabricante Leica Geosystem, que realiza mensurações verticais para determinação de desníveis, recalques, cotas, etc. sua precisão, para míras de ínvar, é de $0,3 \mathrm{~mm} / \mathrm{Km}$ e de $1,0 \mathrm{~mm} / \mathrm{km}$ para míras convencionais (Leica, 2004).

A segunda etapa foi repetir este experimento utilizando o SAND. Os dados deste levantamento foram comparados com o anterior para a realização das análises necessárias para validar o sistema. Realizou-se também uma etapa de testes para verificação de operação do equipamento em condições de pouca luminosidade.

A área escolhida para a realização dos ensaios localiza-se no corredor do bloco VI, nas proximidades do Laboratório de Instrumentação Geodésica (LAIG), localizada no Centro Politécnico, da UFPR. A escolha deste local deve-se ao fato de o equipamento, por se tratar de um protótipo e não possuir baterias, necessitar de energia elétrica para alimentar os motores de passo, além do fato de o laboratório possuir a infraestrutura necessária (computadores, tomadas e periféricos) para apoiar a realização dos testes. 
Para a realização dos testes foram confeccionados 6 (seis) alvos com códigos de barras, réplicas de uma mira de ínvar do fabricante Leica, com 0,886 m de comprimento e com $0,042 \mathrm{~m}$ de largura. Alguns alvos foram confeccionados com 0,063 $\mathrm{m}$ de largura, aumentando assim a área para a pontaria do nível. Os alvos foram impressos em papéis adesivos e colados em chapas de poliestireno standard (PS) cujas principais características são a boa resistência ao impacto frontal, excelente difusão da luz, perfeita reprodução da superfície gravada, elevada flexibilidade e ótima estabilidade dimensional.

A necessidade do uso dos alvos confeccionados se dá pela proposta deste trabalho de pesquisa que fará uso de alvos acoplados nas paredes ao longo do corredor do bloco VI. As simulações de recalques implicam na mudança do posicionamento vertical dos alvos através de furos feitos nos mesmos. Este procedimento, caso fosse feito com as miras de ínvar, causariam avarias a estas. Isto justifica a substituição das míras de ínvar pelos alvos (réplicas) confeccionados.

\subsection{Nivelamento geométrico convencional}

Primeiramente realizou-se o nivelamento geométrico, método das visadas extremas (irradiação aos alvos), sem o uso do SAND. Os dados coletados neste levantamento serviram de parâmetros para comparação com o levantamento posteriormente executado com o SAND. Para esta etapa utilizou-se o nível digital DNA 03, um tripé industrial e seis alvos confeccionados.

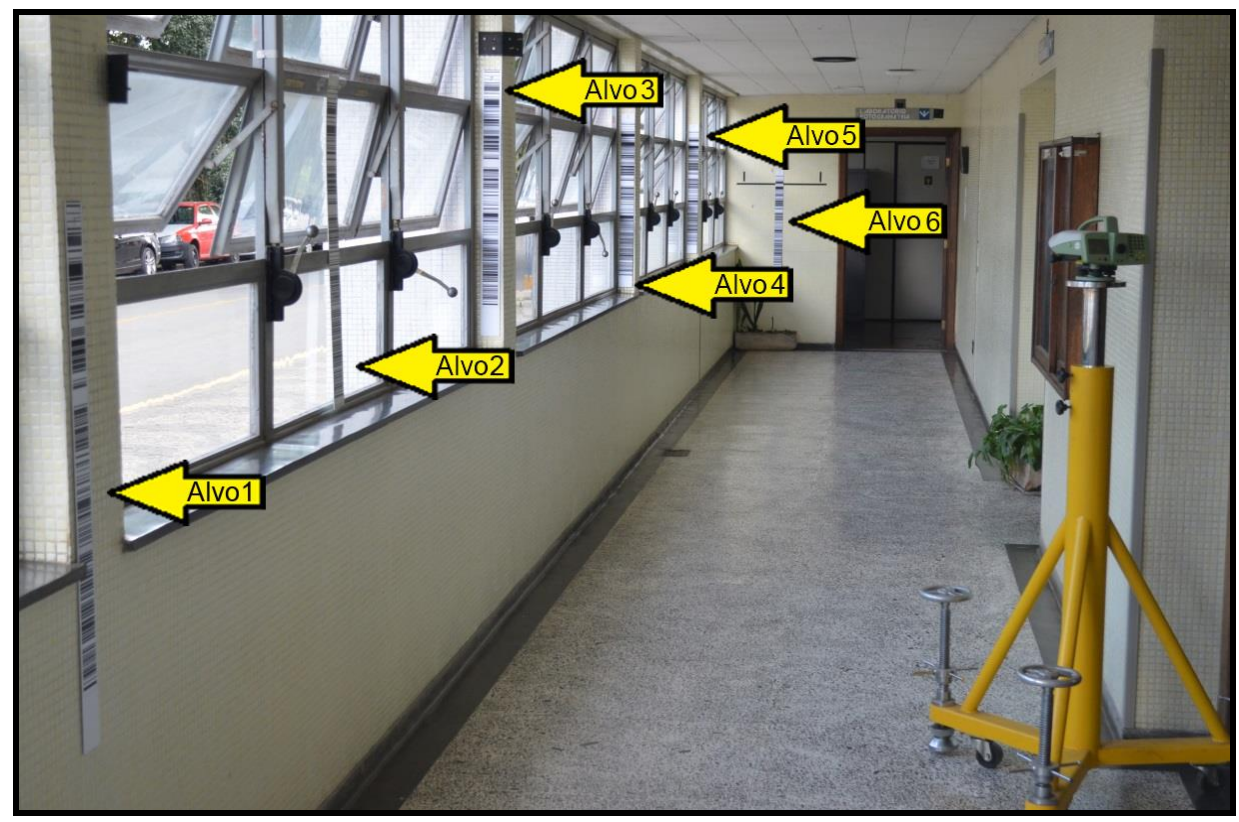

Figura 5: Nivelamento geométrico convencional

Fonte: o autor

Conforme ilustra a Figura 5, os alvos foram posicionados em pontos estrategicamente escolhidos, ao longo do corredor do bloco VI e neles foram realizadas séries de observações. O nível foi colocado na entrada do laboratório, instalado e calado sobre um tripé industrial, em uma posição tal que se pudesse efetuar as visadas em todos os pontos escolhidos, possibilitando a realização dos testes. 
Para a simulação de recalques foram colocados pregos em cada lugar escolhido do corredor. Os alvos receberam pequenos orifícios, para possibilitar a realização de mudança de posição vertical, exemplificado na Figura 6.

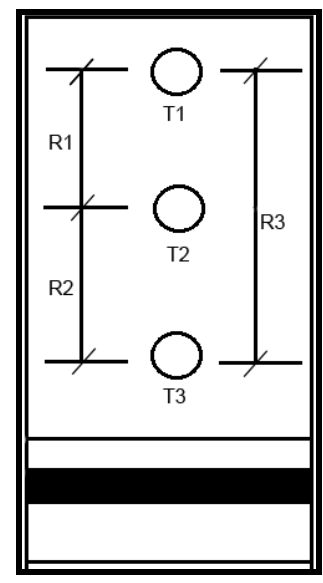

Figura 6: Esquema dos furos nos alvos

Fonte: o autor

Ao orifício superior, denominou-se de posição T1, ao orifício central, denominou-se de posição T2 e, finalmente, ao orifício inferior denominou-se de T3. Desta forma as diferenças observadas entre T1 e T2 foram denominadas de recalque R1. Às diferenças observadas entre T2 e T3 convencionou-se chamar recalque R2 e para as diferenças encontradas entre $\mathrm{T} 1$ e T3, chamou-se R3, como indica a Equação 1, Equação 2 e Equação 3. A Figura 7 ilustra um alvo posicionado no local de testes:

$$
\begin{aligned}
& \mathrm{R} 1=\mathrm{T} 1-\mathrm{T} 2 \\
& \mathrm{R} 2=\mathrm{T} 2-\mathrm{T} 3 \\
& \mathrm{R} 3=\mathrm{T} 1-\mathrm{T} 3
\end{aligned}
$$

Onde:

T1- leitura do alvo quando esta se encontra na posição T1

T2- leitura do alvo quando esta se encontra na posição T2

T3- leitura do alvo quando esta se encontra na posição T3

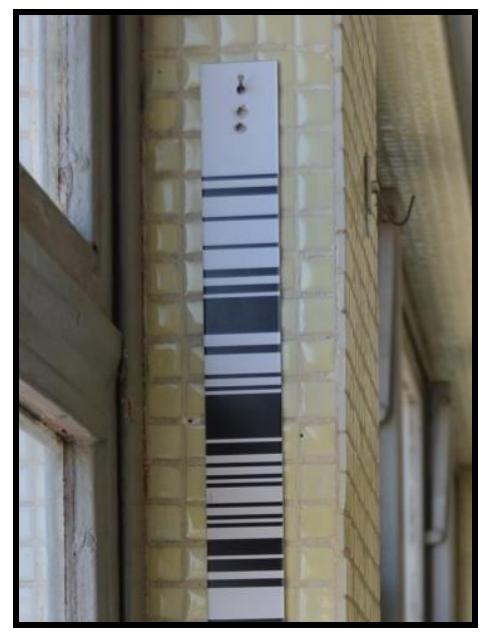

Figura 7: Alvo com furos para possibilitar a simulação de recalques Fonte: o autor 
Ao todo foram realizadas dez observações para cada posição (T1, T2 e T3) do alvo, totalizando 30 (trinta) leituras para cada alvo. O nível foi configurado para efetuar as leituras nos alvos através da média aritmética de três observações, ou seja, cada observação (leitura) que o nível efetuava representava a média aritmética de três leituras consecutivas.

\subsection{Nivelamento geométrico utilizando o SAND}

O nivelamento geométrico com o uso do SAND repetiu os mesmos procedimentos de ensaios empregados no nivelamento geométrico convencional. $\mathrm{O}$ alvo 2 não teve sua posição alterada durante todo o levantamento com o intuito de verificar se as leituras realizadas com SAND se manteriam uniformes durante todo o período do levantamento. Logo, este alvo não foi considerado para o cálculo de recalques.

O equipamento foi configurado para fazer uma série de observações (uma observação para cada alvo, do 1 ao 6) em intervalos de 1 (um) minuto entre as séries. O período de operação do SAND foi de aproximadamente seis horas, coletando aproximadamente 370 (trezentos e setenta) observações de leitura de mira e distância.

\subsection{Teste de resposta do SAND quanto à detecção dos alvos em ambientes com pouca iluminação}

Outra preocupação da utilização deste sistema relaciona-se com a iluminação do local do trabalho. Para simular condições de iluminação desfavoráveis, quatro alvos foram dispostos no corredor do bloco VI, e o equipamento foi posicionado na entrada do LAIG.

O teste foi iniciado com iluminação natural e prosseguindo até o anoitecer com a utilização de iluminação artificial, conforme mostrado na Figura 8.

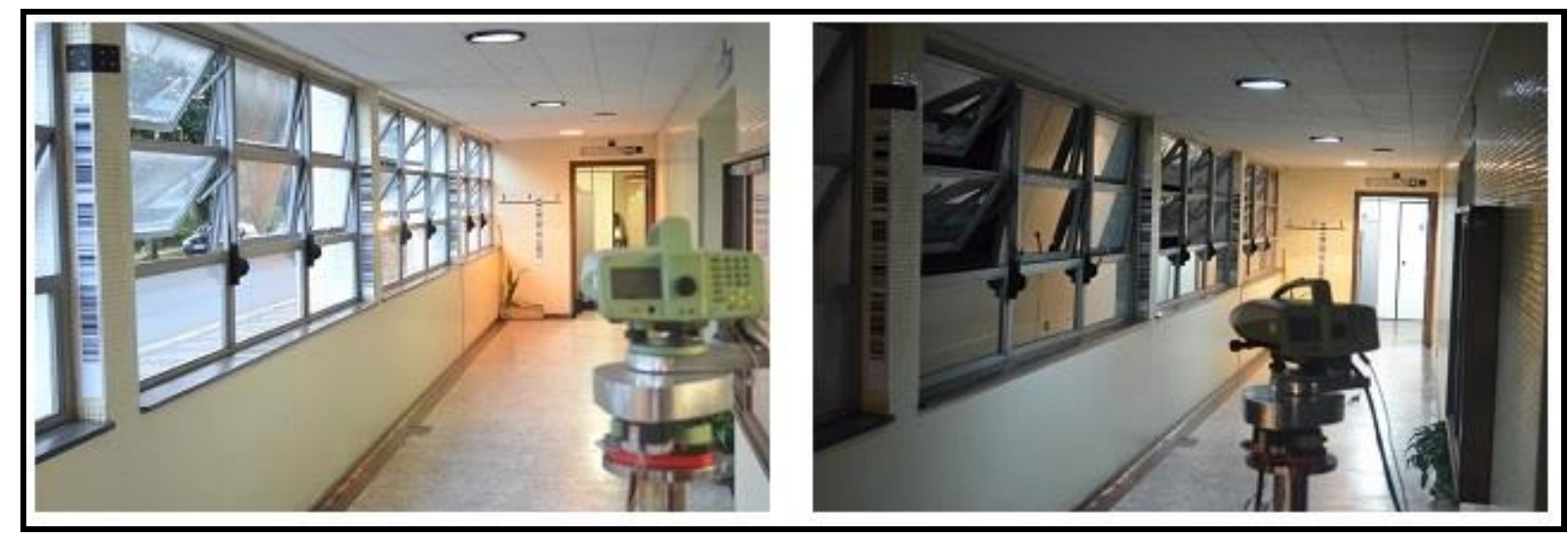

Figura 8: Condições de iluminação dos alvos durante a realização dos testes Fonte: o autor 
Os dados coletados durante o período de observação foram divididos em duas amostras, sendo uma para o período da tarde e outra para o período da noite. Destas amostras foram determinadas a média e o desvio padrão dos recalques, sendo estes calculados seguindo o procedimento das Equações 1, 2 e 3.

\section{Resultados e análises}

De posse dos dados referentes às posições T1, T2 e T3 de cada alvo, obtiveram-se os recalques R1, R2 e R3, tanto para o nivelamento geométrico convencional quanto para o nivelamento geométrico com o uso do SAND, conforme as Equações 1, 2 e 3. Realizou-se também o cálculo de propagação das covariâncias em cada um dos alvos para estimar os desvios-padrão dos recalques, através da fórmula (Gemael, 1994; Dalmolin, 2004):

$$
\sum Y=G \cdot \sum X \cdot G^{T}
$$

Onde:

$G$ - Matriz das incógnitas ou jacobiana;

$\sum X$ - Matriz variância/covariância dos "erros" (variáveis);

$\sum Y$ - Matriz variância/covariância da variável dependente Y.

Os valores dos recalques obtidos destes dois ensaios foram posteriormente comparados para verificar se houve uma significativa diferença nos resultados obtidos. Ressalta-se aqui que o alvo 2 não participou do processo de cálculo de recalque uma vez que não teve sua posição alterada durante todo o levantamento. As tabelas 1 e 2 mostram os valores para os recalques R1, R2 e R3 obtidos para o nivelamento geométrico convencional e para o nivelamento geométrico com o uso do SAND e seus respectivos desvios-padrão:

Tabela 1: Recalques obtidos utilizando nivelamento geométrico convencional

\begin{tabular}{c|c|c|c|c|c|c}
\hline Alvo & $\mathrm{R} 1(\mathrm{~mm})$ & $\sigma_{R 1}(\mathrm{~mm})$ & $\mathrm{R} 2(\mathrm{~mm})$ & $\sigma_{R 2}(\mathrm{~mm})$ & $\mathrm{R} 3(\mathrm{~mm})$ & $\sigma_{R 3}(\mathrm{~mm})$ \\
\hline 1 & 3,34 & 0,05 & 8,08 & 0,04 & 11,42 & 0,04 \\
\hline 3 & 2,88 & 0,04 & 6,41 & 0 & 9,29 & 0,04 \\
\hline 4 & 7,99 & 0,03 & 6,4 & 0 & 14,39 & 0,03 \\
\hline 5 & 5,82 & 0,04 & 7,84 & 0,03 & 13,66 & 0,03 \\
\hline 6 & 14,4 & 0 & 14,1 & 0 & 28,5 & 0 \\
\hline
\end{tabular}


Tabela 2: Recalques obtidos com nivelamento geométrico utilizando o SAND

\begin{tabular}{c|c|c|c|c|c|c}
\hline Alvo & $\mathrm{R} 1(\mathrm{~mm})$ & $\sigma_{R 1}(\mathrm{~mm})$ & $\mathrm{R} 2(\mathrm{~mm})$ & $\sigma_{R 2}(\mathrm{~mm})$ & $\mathrm{R} 3(\mathrm{~mm})$ & $\sigma_{R 3}(\mathrm{~mm})$ \\
\hline 1 & 3,70 & 0,07 & 7,75 & 0,05 & 11,45 & 0,05 \\
\hline 3 & 2,70 & 0,04 & 6,41 & 0,03 & 9,13 & 0,05 \\
\hline 4 & 8,00 & 0 & 6,30 & 0 & 14,30 & 0 \\
\hline 5 & 5,99 & 0,07 & 7,64 & 0,08 & 13,63 & 0,08 \\
\hline 6 & 14,28 & 0,10 & 14,01 & 0,08 & 28,30 & 0,11 \\
\hline
\end{tabular}

Durante o processo de nivelamento geométrico convencional, os valores de leitura do alvo 3 e do alvo 4 na posição T2 não sofreram variações durante o processo de coleta de amostras. Do mesmo modo, os valores de leitura do alvo 6 nas posições T1, T2 e T3 também não sofreram variações durante o registro de observações. Estes fatos justificam os valores de variâncias nulas (valor de desvio padrão igual a zero) calculadas pelo procedimento de propagação das covariâncias mostrados na tabela 1 . No decorrer do processo de nivelamento geométrico utilizando o SAND, os valores de leitura observados no alvo 4 nas posições T1,T2 e T3 não sofreram variações ou discrepâncias, o que justifica o valor de desvio padrão nulo para os recalques calculados no processo de propagação de covariâncias mostrado na tabela 2.

Os gráficos a seguir ilustram melhor a comparação dos valores de recalque, em milímetros, dos dados coletados tanto no nivelamento convencional quanto no nivelamento com o SAND. A Figura 9 ilustra a diferença nos valores de recalque R1, enquanto que a Figura 10 ilustra a diferença nos valores de recalque R2 e a Figura 11 mostra a diferença nos valores de recalque R3.

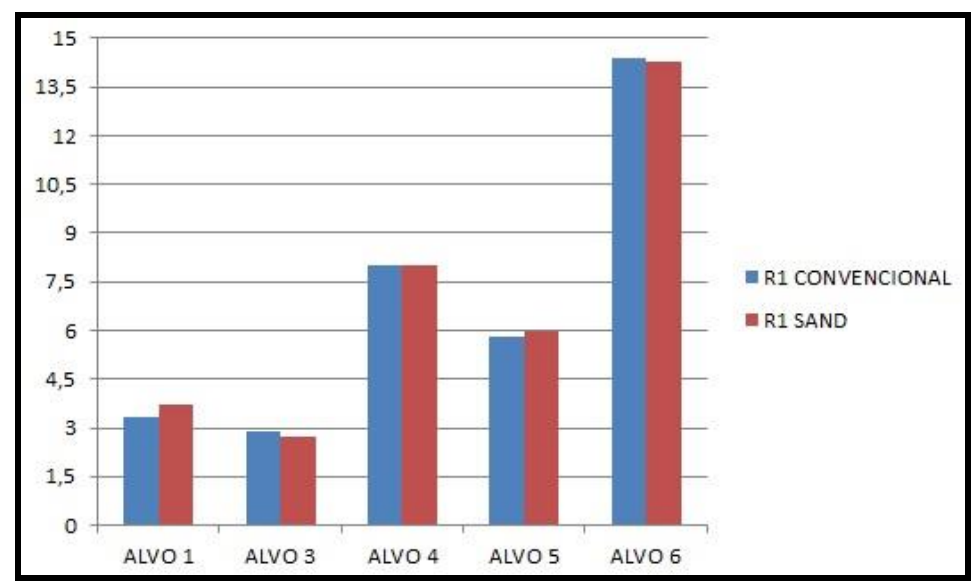

Figura 9: Gráfico de comparação dos valores de recalque R1 entre o nivelamento convencional e o SAND 


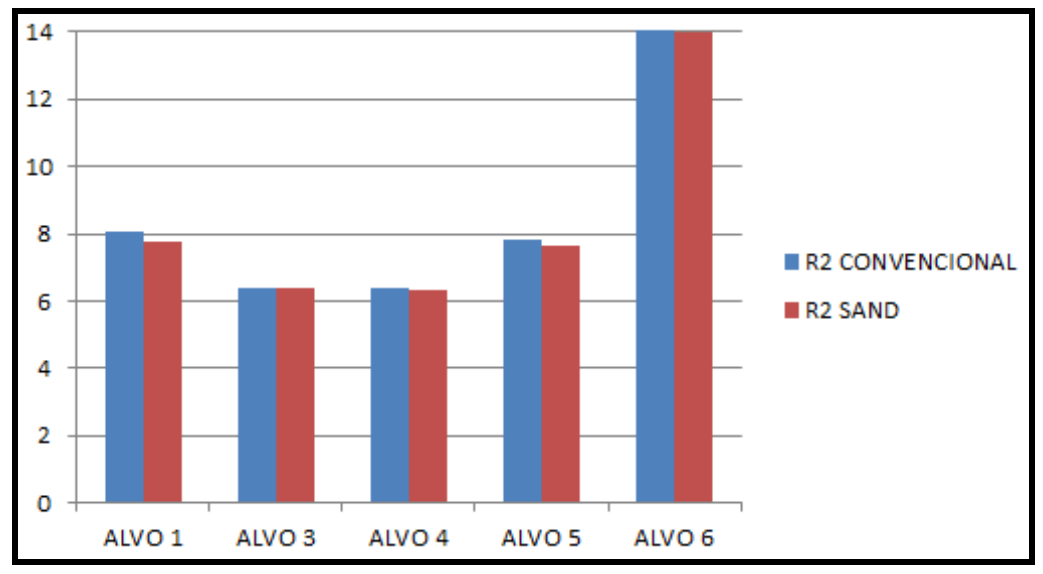

Figura 10: Gráfico de comparação dos valores de recalque R2 entre o nivelamento convencional e o SAND

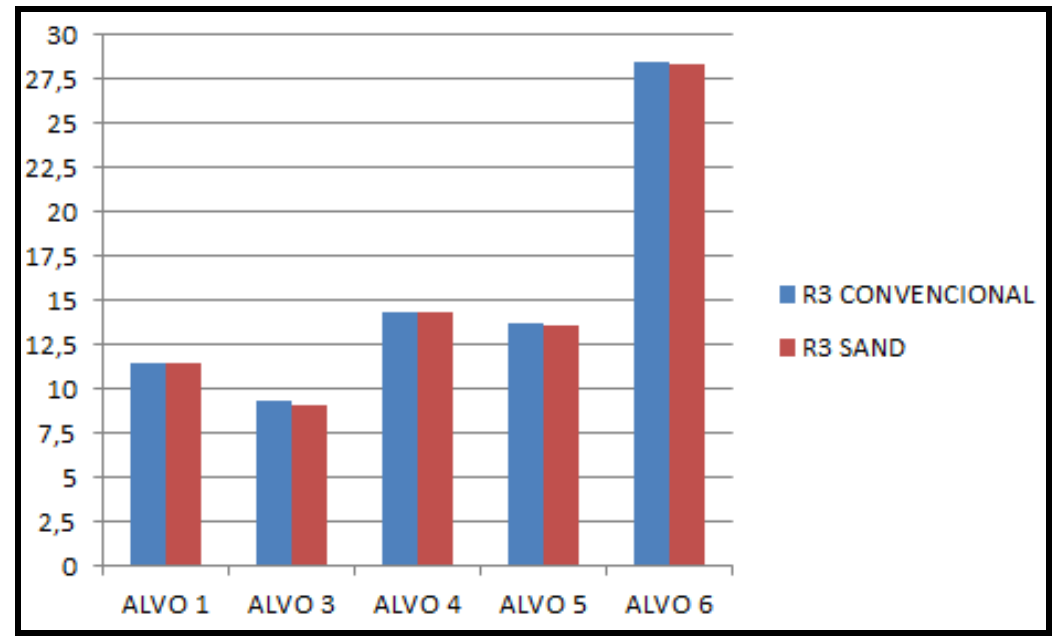

Figura 11: Gráfico de comparação dos valores de recalque R3 entre o nivelamento convencional e o SAND

A tabela 3 mostra as diferenças, em milímetros, entre os recalques calculados com o nivelamento geométrico convencional e o nivelamento geométrico com o uso do SAND:

Tabela 3: diferenças entre os valores de recalques obtidos com o nivelamento geométrico convencional e com o SAND

\begin{tabular}{c|c|c|c}
\hline ALVOS & R1 $(\mathrm{mm})$ & $\mathrm{R} 2(\mathrm{~mm})$ & $\mathrm{R} 3(\mathrm{~mm})$ \\
\hline 1 & 0,36 & 0,33 & $-0,03$ \\
\hline 3 & 0,18 & 0,00 & 0,16 \\
\hline 4 & $-0,01$ & 0,10 & 0,09 \\
\hline 5 & $-0,17$ & 0,20 & 0,03 \\
\hline 6 & 0,12 & 0,09 & 0,20 \\
\hline
\end{tabular}

A variação entre os recalques calculados pelos dois métodos foi da ordem do décimo do milímetro ou menor, mostrando forte consistência entre os dados obtidos com o nivelamento convencional e os dados obtidos com o nivelamento utilizando o SAND.

Outra análise realizada teve como base as normas do IBGE, PR $n^{\circ} 22$. Esta norma, no que concerne aos levantamentos altimétricos, diz que (IBGE, 1983): 
Para levantamentos altimétricos de $1^{\circ}$ ordem a exatidão deve ser superior a $2 m m \sqrt{k}$;

Para levantamentos altimétricos de $2^{\circ}$ ordem a exatidão deve ser superior a $3 m m \sqrt{k}$;

Para levantamentos de $3^{\circ}$ ordem a exatidão deve ser superior a $4 m m \sqrt{k}$;

Para levantamentos topográficos a exatidão deve ser superior a $6 m m \sqrt{k}$.

Sendo $k$ a média do caminhamento percorrido do nivelamento e contra-nivelamento em quilômetros. A tabela 4 mostra os resultados dos erros admissíveis dos recalques calculados de cada alvo em função da distância em relação ao equipamento, segundo a norma.

Tabela 4: valores dos erros admissíveis para os alvos

\begin{tabular}{c|c|c|c|c}
\hline ALVO & $1^{\circ}$ ordem $(\mathrm{mm})$ & $2^{\circ}$ ordem $(\mathrm{mm})$ & $3^{\circ}$ ordem $(\mathrm{mm})$ & Topográfico $(\mathrm{mm})$ \\
\hline 1 & 0,11 & 0,16 & 0,21 & 0,32 \\
\hline 3 & 0,10 & 0,15 & 0,20 & 0,31 \\
\hline 4 & 0,15 & 0,23 & 0,31 & 0,46 \\
\hline 5 & 0,20 & 0,30 & 0,39 & 0,59 \\
\hline 6 & 0,23 & 0,35 & 0,47 & 0,70 \\
\hline
\end{tabular}

Valendo-se deste critério, as variações encontradas para a grande maioria das diferenças entre os recalques calculados em ambos os ensaios (nivelamento geométrico convencional e nivelamento geométrico com o uso do SAND) estão dentro da precisão do método. Apenas os recalques R1 e R2 do alvo 1 extrapolaram o limite da norma, ainda assim, apenas no centésimo do milímetro. Os valores da diferença entre os recalques dos alvos 4, 5 e 6 oscilaram dentro do intervalo permitido para um levantamento de $1^{\circ}$ ordem, muito embora não tenham sido utilizadas nos ensaios míras de ínvar, mas sim réplicas. Para o alvo 3 os valores referentes às diferenças entre recalques R1 e R3 oscilaram dentro do limite para um levantamento altimétrico de terceira ordem.

As tabelas 5 e 6, referentes ao teste do SAND quanto à detecção de alvos em ambientes com pouca luminosidade, mostram a média dos recalques calculados juntamente com o desvio padrão para cada um dos alvos, em suas diferentes posições, tanto no período diurno quanto no período noturno:

Tabela 5: média e desvio padrão dos recalques no período diurno

\begin{tabular}{c|c|c|c|c|c|c}
\hline ALVO & R1 $(\mathrm{mm})$ & $\sigma^{2}(\mathrm{R} 1) \mathrm{mm}$ & $\mathrm{R} 2(\mathrm{~mm})$ & $\sigma^{2}(\mathrm{R} 2) \mathrm{mm}$ & $\mathrm{R} 3(\mathrm{~mm})$ & $\sigma^{2}(\mathrm{R} 3) \mathrm{mm}$ \\
\hline 1 & 3,41 & 0,03 & 5,8 & 0 & 9,21 & 0,03 \\
\hline 2 & 7,8 & 0,11 & 6,92 & 0,07 & 14,74 & 0,11 \\
\hline 3 & 5,73 & 0,17 & 7,78 & 0,05 & 13,6 & 0,2 \\
\hline 4 & 14,7 & 0,11 & 13,69 & 0,08 & 28,37 & 0,08 \\
\hline
\end{tabular}


Tabela 6: média e desvio padrão dos recalques no período noturno

\begin{tabular}{c|c|c|c|c|c|c}
\hline ALVO & R1 $(\mathrm{mm})$ & $\sigma^{2}(\mathrm{R} 1) \mathrm{mm}$ & $\mathrm{R} 2(\mathrm{~mm})$ & $\sigma^{2}(\mathrm{R} 2) \mathrm{mm}$ & $\mathrm{R} 3(\mathrm{~mm})$ & $\sigma^{2}(\mathrm{R} 3) \mathrm{mm}$ \\
\hline 1 & 3,27 & 0,05 & 6,01 & 0,03 & 9,26 & 0,05 \\
\hline 2 & 8,41 & 0,03 & 6,32 & 0,07 & 14,73 & 0,05 \\
\hline 3 & 5,9 & 0,05 & 7,98 & 0,1 & 13,87 & 0,09 \\
\hline 4 & 14,62 & 0,07 & 13,99 & 0,15 & 28,51 & 0,2 \\
\hline
\end{tabular}

A tabela 7 mostra as diferenças nos recalques calculados para os alvos entre o período noturno e diurno:

Tabela 7: diferença entre os recalques calculados no período diurno e noturno

\begin{tabular}{c|c|c|c}
\hline ALVO & R1 $(\mathrm{mm})$ & $\mathrm{R} 2(\mathrm{~mm})$ & $\mathrm{R} 3(\mathrm{~mm})$ \\
\hline 1 & 0,14 & $-0,21$ & $-0,05$ \\
\hline 2 & $-0,61$ & 0,60 & 0,01 \\
\hline 3 & $-0,17$ & $-0,20$ & $-0,27$ \\
\hline 4 & 0,08 & $-0,30$ & $-0,14$ \\
\hline
\end{tabular}

A diferença entre os recalques calculados para o período diurno e noturno foi da ordem do décimo de milímetro ou menor, mostrando a confiabilidade do SAND para leituras em ambientes com pouca iluminação.

\subsection{Análise da variância das amostras}

Para uma melhor análise sobre os dados coletados nos ensaios, recorreram-se às inferências estatísticas, utilizando o teste F de Snedecor ao nível de significância de 5\% (Guerra e Donaire, 1982), para testar se há diferenças significativas entre as variâncias $\sigma_{1}^{2}$ e $\sigma_{2}^{2}$ das observações coletadas, sendo $\sigma_{1}^{2}$ a variância das amostras coletadas referente às observações realizadas pela metodologia clássica de nivelamento geométrico e $\sigma_{2}^{2}$ a variância do conjunto amostral do nivelamento efetuado com o SAND.

O teste F de Snedecor é utilizado para verificar a igualdade entre duas variâncias populacionais (Guerra e Donaire, 1982). Este teste possibilita verificar, dentro de certo nível de significância, se há diferenças significativas na precisão da determinação dos recalques para cada um dos alvos.

Para o teste de igualdade de duas variâncias populacionais $\sigma_{1}^{2}$ e $\sigma_{2}^{2}$, formula-se a hipótese nula supondo as duas variâncias iguais:

$$
H_{0}: \sigma_{1}^{2}=\sigma_{2}^{2}
$$

A hipótese alternativa será formulada supondo-se as variâncias do conjunto amostral sendo diferentes:

$$
H_{1}: \sigma_{1}^{2} \neq \sigma_{2}^{2}
$$


Nestas condições, onde o que será testado entre as variâncias será apenas a sua condição de igualdade $\left(H_{0}: \sigma_{1}^{2}=\sigma_{2}^{2}\right)$ ou diferença $\left(H_{1}: \sigma_{1}^{2} \neq \sigma_{2}^{2}\right)$, o teste de hipótese será bilateral.

A variável escolhida é "F" de Snedecor, sendo $\phi_{1}=n_{1}-1$ graus de liberdade no numerador e $\phi_{2}=n_{2}-1$ graus de liberdade no denominador. O nível de significância adotado é de $5 \%$.

$$
F=\left(\frac{S_{1}^{2}}{S_{2}^{2}}\right) *\left(\frac{\sigma_{1}^{2}}{\sigma_{2}^{2}}\right)
$$

Como $\sigma_{1}^{2}=\sigma_{2}^{2}$, então:

$$
F=\left(\frac{S_{1}^{2}}{S_{2}^{2}}\right)
$$

Sendo:

$S_{1}^{2}$ e $S_{2}^{2}$ as variâncias amostrais.

Como já mencionado, o número de significância utilizado é de $5 \%$, ou 0,05 . Então $\alpha / 2$ é igual a 0,025 para um teste bilateral. A aplicação do teste consiste em calcular, por meio da Equação 8, a estatística $\mathrm{F}$, e comparando seu valor a $\mathrm{F} \alpha / 2$, que se trata de um valor tabelado. Os valores de $\mathrm{F}$ calculados são confrontados com os valores da tabela $\mathrm{F}$ de SNEDECOR, valores estes que variam de acordo com o grau de liberdade das amostras. Para que a hipótese nula seja aceita, é necessário que sua variável estatística $\mathrm{F}$ (razão entre as variâncias das amostras) esteja no intervalo de $\mathrm{F} \alpha / 2$ e $1-\mathrm{F} \alpha / 2$.

Para o caso em que foram comparadas as variâncias do conjunto amostral tanto do nivelamento geométrico convencional quanto do nivelamento com o uso do SAND, a tabela 8 apresenta os resultados do teste de hipótese aplicado para as variâncias dos recalques calculados nos dois ensaios realizados:

Tabela 8: resultados do teste de hipótese para os recalques calculados

\begin{tabular}{c|c|c|c}
\hline ALVO & R1 & R2 & R3 \\
\hline 1 & $H_{0}: \sigma_{1}^{2}=\sigma_{2}^{2}$ & $H_{0}: \sigma_{1}^{2}=\sigma_{2}^{2}$ & $H_{0}: \sigma_{1}^{2}=\sigma_{2}^{2}$ \\
\hline 3 & $H_{0}: \sigma_{1}^{2}=\sigma_{2}^{2}$ & $H_{0}: \sigma_{1}^{2}=\sigma_{2}^{2}$ & $H_{0}: \sigma_{1}^{2}=\sigma_{2}^{2}$ \\
\hline 4 & $H_{1}: \sigma_{1}^{2} \neq \sigma_{2}^{2}$ & $H_{1}: \sigma_{1}^{2} \neq \sigma_{2}^{2}$ & $H_{1}: \sigma_{1}^{2} \neq \sigma_{2}^{2}$ \\
\hline 5 & $H_{0}: \sigma_{1}^{2}=\sigma_{2}^{2}$ & $H_{0}: \sigma_{1}^{2}=\sigma_{2}^{2}$ & $H_{0}: \sigma_{1}^{2}=\sigma_{2}^{2}$ \\
\hline 6 & $H_{1}: \sigma_{1}^{2} \neq \sigma_{2}^{2}$ & $H_{1}: \sigma_{1}^{2} \neq \sigma_{2}^{2}$ & $H_{1}: \sigma_{1}^{2} \neq \sigma_{2}^{2}$ \\
\hline
\end{tabular}

Os resultados obtidos mostram que para os alvos 1, 3 e 5 os recalques foram determinados com o mesmo grau de precisão. Já para os alvos 4 e 6 houve uma diferença estatística na determinação de seus recalques. Ressalta-se aqui que as variâncias calculadas para as amostras de recalques dos ensaios foram pequenas e os desvios-padrão foram da ordem do décimo do milímetro, o que representa boa qualidade.

Para o caso da análise estatística realizada sobre os resultados obtidos nos ensaios para verificação da resposta do SAND em ambientes com pouca iluminação, foi considerada como hipótese nula a igualdade entre as variâncias amostrais dos ensaios realizados nos períodos 
diurno e noturno $\left(H_{0}: \sigma_{1}^{2}=\sigma_{2}^{2}\right)$ e como hipótese alternativa a diferença entre essas $\left(H_{1}: \sigma_{1}^{2} \neq\right.$ $\left.\sigma_{2}^{2}\right)$.

A tabela 9 mostra os resultados dos testes de análise das variâncias das amostras, apenas com o SAND, para avaliar o comportamento do equipamento em condições de baixa iluminação:

Tabela 9: teste f de snedecor para igualdade de variância das amostras

\begin{tabular}{c|c|c|c}
\hline ALVO & R1 & R2 & R3 \\
\hline 1 & $H_{0}: \sigma_{1}^{2}=\sigma_{2}^{2}$ & $H_{1}: \sigma_{1}^{2} \neq \sigma_{2}^{2}$ & $H_{0}: \sigma_{1}^{2}=\sigma_{2}^{2}$ \\
\hline 2 & $H_{1}: \sigma_{1}^{2} \neq \sigma_{2}^{2}$ & $H_{0}: \sigma_{1}^{2}=\sigma_{2}^{2}$ & $H_{1}: \sigma_{1}^{2} \neq \sigma_{2}^{2}$ \\
\hline 3 & $H_{1}: \sigma_{1}^{2} \neq \sigma_{2}^{2}$ & $H_{0}: \sigma_{1}^{2}=\sigma_{2}^{2}$ & $H_{1}: \sigma_{1}^{2} \neq \sigma_{2}^{2}$ \\
\hline 4 & $H_{0}: \sigma_{1}^{2}=\sigma_{2}^{2}$ & $H_{0}: \sigma_{1}^{2}=\sigma_{2}^{2}$ & $H_{0}: \sigma_{1}^{2}=\sigma_{2}^{2}$ \\
\hline
\end{tabular}

A maioria dos recalques calculados passou no teste estatístico. Ressalta-se mais uma vez que as variâncias das observações são muito pequenas, o que pode justificar a fato de alguns recalques terem sua hipótese nula rejeitada.

\section{Conclusões}

O objetivo deste trabalho foi validar um sistema de automação de nível digital (SAND) desenvolvido em uma tese de doutorado (Andolfato, 2010). Dois ensaios foram realizados, um utilizando a técnica de nivelamento geométrico com visadas extremas na sua forma convencional, com um técnico operando o nível digital, e o outro utilizando uma proposta de automação da técnica de nivelamento através do uso do SAND, na qual o equipamento opera sozinho durante o período de observação dos alvos. Foram utilizados para estes experimentos seis réplicas de uma míra de invar do fabricante Leica, com pequenos furos em suas partes superiores que possibilitaram a simulação de recalques.

As comparações entre os recalques calculados do Nivelamento Geométrico Convencional e do Nivelamento Geométrico com o uso do SAND apresentaram resultados bastante semelhantes, variando na casa do décimo do milímetro. As precisões das leituras obtidas com o SAND foram da ordem de décimos de milímetros ou superiores, assim como as precisões obtidas no nivelamento convencional. Os valores determinados foram submetidos a testes de hipóteses para verificar a igualdade de precisão de ambos os métodos e a maior parte dos recalques passou no teste estatístico. Pelas normas do IBGE, a variação da grande maioria dos dados oscilou dentro do limite da precisão do método.

O SAND mostrou-se bastante eficiente na detecção de alvos em ambientes com pouca iluminação. A diferença nos recalques calculados tanto para o período diurno quanto para o período noturno variou na ordem de grandeza do décimo do milímetro ou menor. Testes de hipóteses foram aplicados para verificar a estabilidade das observações quanto à precisão, sendo que a maioria dos dados teve sua hipótese nula $\left(H_{0}: \sigma_{1}^{2}=\sigma_{2}^{2}\right)$ aceita, o que significa que foram determinados com o mesmo grau de precisão. Destaca-se que as variâncias das observações 
foram pequenas, o que pode justificar os recalques que não passaram no teste estatístico. Os desvios-padrão calculados foram da ordem do décimo do milímetro ou inferior, o que representa uma boa qualidade para os recalques determinados.

\section{REFERÊNCIAS BIBLIOGRÁFICAS}

Aksamitauskas, Vladislovas Ceslovas., Rekus, Donatas., Gynodis, Vytautas. "Application of digital automatic levels and impact of their accuracy on construction measurements" (Paper presented at the 25 International Symposium on Automation and Robotics in Construction, Vilnius, Lithuania, June 26-29, 2008).

Andolfato, Silvio Henrique Delepostte. "Sistema de Automação de Nìvel Digital" (tese de doutorado, Universidade Federal do Paraná, 2010).

Angerer-CPS. “Motorised Digital Levelling Instrument. ” Último aceso em 13 de março de 2015. http://www.angerer-cps.com/pdf/digi_niv_uk.pdf

Corrêa, Cícero Pimentel. "Metodologia para Controle de Recalques em Estruturas de Concreto Armado por meio de Nivelamento Geométrico de Precisão" (dissertação de mestrado, Universidade Federal de Santa Maria, 2012).

Dalmolin, Q. Ajustamento por Mínimos Quadrados. Curitiba: editora UFPR,2 edição, 2004.

Gemael, Camil. Introdução ao Ajustamento de Observações: Aplicações Geodésicas. Curitiba, editora UFPR, 1994.

Guerra, Maurício J., Donaire, Denis. Estatística Indutiva: Teoria e aplicações. São Paulo: LCTE, 1982.

Ghilani, Charles D., Wolf, Paul Richard. Elementary Surveiyng- An Introduction to Geomatics. New Jersey: Pentrice Hall, 2012.

Granemann, Daniel Carvalho. "Estabelecimento de uma Rede Geodésica para Monitoramento de Estruturas: Estudo de caso na Usina Hidrelétrica Salto Caxias". (dissertação de mestrado, Universidade Federal do Paraná, 2005).

IBGE. Especificações e Normas para Levantamentos Geodésicos- PR n ${ }^{\circ} 22$. Rio de Janeiro, 1983.

Kahmen, Heribert; Faig, Wolfgang. Surveiyng. Berlim: Walter de Gruytier, 1988.

Kuang, S. Geodetic Network Analysis and Optimal Design: Concepts and Applications. Michigan: Ed. Ann Arbor Press, 1996.

Leica. DNA03/DNA10 - Manual do Usuário. Versão 1.2 - Leica, 2004.

Milititsky, Jarbas; Consoli, Nilo Cesar; Schnaid, Fernando. Patologia das Fundações. São Paulo: Oficina de textos, 2008.

Miranda, Fabiani das Dores Abati. "Monitoramento Topográfico em Tempo Real com a Utilização de um Sistema Semi Automatizado." (tese de doutorado, Universidade Federal do Paraná, 2012).

Nadal, Marco Aurélio Debus. "Controle e operações de estações totais robotizadas voltados à auscultação geodésica”. (dissertação de mestrado, Universidade Federal do Paraná, 2008). 
Pellegrinelli, A., Furini, A., Bonfè, M., Russo, P. "Motorised digital levels: development and applications." Survey Review 330 (2013), 174-89. DOI:10.1179/1752270612Y.0000000039

Solexperts. "Motion-Controlled Leica and Zeiss Optical Digital Levels". Último acesso em 13 de março de 2015. http://www.solexperts.com

Veiga, Luis Augusto Koenig. "Sistema para mapeamento automatizado em campo: Conceitos, Metodologia e Implantação de um protótipo". (Tese de doutorado, Universidade de São Paulo, 2000).

Recebido em 8 de dezembro de 2015.

Aceito em 6 de novembro de 2016. 